\title{
Familial and Special Twin Influences on Cigarette Use Initiation
}

\author{
Cristina B. Bares, ${ }^{1}$ Hermine H. Maes, ${ }^{2,3}$ and Kenneth S. Kendler ${ }^{2}$ \\ ${ }^{1}$ School of Social Work, University of Michigan, Ann Arbor, Michigan, USA \\ ${ }^{2}$ Virginia Institute for Behavioral and Psychiatric Genetics, Virginia Commonwealth University, Richmond, Virginia, USA \\ ${ }^{3}$ Massey Cancer Institute, Virginia Commonwealth University, Richmond, Virginia, USA
}

\begin{abstract}
Background: Shared experiences within families play an important role in the initiation of cigarette use among adolescents. Behavioral genetic studies using various samples have implicated that the shared environment that twins experience is an important source of influence on whether adolescents initiate cigarette use. Whether the special twin environment, in addition to the shared environment, contributes significantly to making twin siblings more similar in cigarette initiation, and whether the influence of the special twin environment persists into adulthood, is less clear. Methods: Data for this study came from the National Longitudinal Survey of Adolescent Health. Twin, full-, and half-sibling pairs between the ages of 12 and 33 were separated into three age groups, with about 3,000 individuals in each age group. The proportion of variance in cigarette use initiation explained by genetic, shared, special twin, and unique environmental factors were examined. Results: The results of separate age-moderated univariate variance decomposition models indicate that the special twin environment does not significantly contribute to the variance in cigarette use initiation in adolescence or young adulthood. Conclusion: Factors shared by individuals in a family, but that are not specific to being a twin, are important in determining whether adolescents will initiate the use of cigarettes.
\end{abstract}

Keywords: adolescence, cigarette initiation, special twin environment, shared environment

Adolescence is a vulnerable developmental time for the onset of regular cigarette use (Substance Abuse and Mental Health Services Administration, 2007) and for the development of nicotine dependence (U.S. Department of Health and Human Services, 1994). Despite substantial decreases in the prevalence of 30-day cigarette use during adolescence (Johnston et al., 2013; 2015), the majority of adults report initiating cigarette use during adolescence. Epidemiological studies have suggested that cigarette use by siblings (Bricker et al., 2006; Gilman et al., 2009; O’Loughlin et al., 2009) is an important influence on adolescents' initiation, and use of, cigarettes. Having a sibling who is a smoker increases the chances that adolescents will initiate the use of cigarettes (Avenevoli \& Merikangas, 2003; Rohde et al., 2003). Further, siblings of individuals who are habitual smokers have higher rates of cigarette use than siblings of controls (Bierut et al., 1998), and having a twin or a sibling who uses cigarettes is a predictor of initiating cigarette use (Vink et al., 2003).

In genetically informed studies that employ twins, the shared environment $\left(c^{2}\right)$ refers to aspects of the environment that are responsible for making siblings within the same family similar, while the non-shared environment refers to factors responsible for making siblings in the same family different from one another. Aspects of the familial environment common to both siblings include the experience of parent-child conflict (Burt et al., 2003) or experiencing parental divorce (Burt et al., 2008; D’Onofrio et al., 2005). Shared environmental influences that are considered to make twins more similar to each other account for over a third of the stability in psychopathology in childhood and adolescence (Bartels et al., 2004).

Classical twin studies include data from pairs of monozygotic (MZ) and dizygotic (DZ) twins and can be extended by including pairs of individuals that differ in their genetic relatedness, but who experience the same familial environment. For instance, full-siblings are as genetically related to one another as pairs of DZ twins and share $50 \%$ of their genes, while half-siblings share

RECEIVED 12 November 2016; ACCEPTED 11 January 2017

ADDRESS FOR CORRESPONDENCE: Cristina B. Bares, School of Social Work, The University of Michigan, 1080 S. University, Ann Arbor, MI 48109, USA. E-mail: cbb@umich.edu 
$25 \%$ of their segregating genes. When reared in the same home environment, MZ and DZ twins, as well as fullsiblings, share $100 \%$ of their rearing environment. Due to disruptions in living situations, half-siblings do not experience the same rearing environment as one another. Adding full-sibling and half-sibling pairs in a genetically informed analysis provides an additional contrast of genetic relatedness and allows for the effect of the special twin environment $\left(\mathrm{t}^{2}\right)$ to be estimated in addition to the effect of the shared environment $\left(c^{2}\right)$. We define the special twin environment as an influence specific and unique to being a twin that, in addition to the shared environment, has an effect on a phenotype, and makes twins more similar than full-siblings.

Twin studies have established that shared environmental factors $\left(c^{2}\right)$ within a family account for about $34-55 \%$ of the variation in adolescent initiation of cigarette use (Seglem et al., 2015; Unger et al., 2011) and that there is a developmental shift in the factors that influence cigarette use initiation into adulthood (Maes et al., 2016). The strength of the shared environment is strongest in early adolescence. In middle adolescence and continuing on to adulthood, the influence of the shared environment shifts such that additive genetic influences increase in strength (Bares et al., 2015; Maes et al., 1999). Previous studies have found shared environmental influences specific to twins that play a role in the initiation of cigarette use among 12- to 19year-olds (Rhee et al., 2003) and explain 30\% of the variance in regular tobacco use (Young et al., 2006). Further, studies capitalizing on the relatedness of twins and sibling pairs indicate that among pairs that are highly socially connected, that is, have friends in common, the effect of the shared environment on cigarette use is greater (Slomkowski et al., 2005).

Whether the influence of the special twin environment in the initiation of cigarette use extends beyond adolescence and into adulthood has not been explored. Given the importance of the shared environment as a risk factor for the initiation of cigarette use in adolescence, the aims of the present study were to test whether the special twin environment, in addition to the shared environment, has a unique influence on cigarette use initiation, and to examine the developmental specificity of the influence of the special twin environment across adolescence and into adulthood. Due to the larger role that the shared environment plays in the initiation of cigarette use during adolescence relative to genetic factors, we hypothesized that the special twin environment would contribute significantly to the variance in cigarette use initiation in adolescence.

\section{Materials and Methods}

\section{Participants}

For this study, we used data from twin and siblings pairs available in the National Longitudinal Study of Adolescent to Adult Health (Add Health; Harris, 2013; Harris et al., 2013). The Add Health participants are a nationally representative and longitudinal sample of adolescents followed over the course of 20 years through four assessments. Add Health participants provided written informed consent for participation in all aspects of Add Health in accordance with the University of North Carolina School of Public Health Institutional Review Board guidelines that are based on the Code of Federal Regulations on the Protection of Human Subjects 45CFR46.

The initial survey took place when participants were 1217 years of age, and the most recent assessment occurred when participants were 26-33 years old (Harris, 2013). Over 3,000 pairs of the participants, who took part in the Add Health in-school survey lived in the same household (Harris et al., 2009) and were twins, full- or half-siblings, adopted siblings, or unrelated individuals (i.e., foster siblings; Harris et al., 2006; 2013). For this study, data came from pairs of MZ and DZ twins, as well as full- and halfsiblings who lived in the same household at the time of the survey.

\section{Measures}

Cigarette use initiation. Participants were asked to report on whether they had ever smoked a cigarette, even just a puff. A binary variable was created for each participant that indicated whether they had ever smoked a cigarette (coded as 1 ) or not (coded as 0$)$.

Zygosity. The zygosity of each individual in a twin pair was determined through self-reported answers to questions about the degree of similarity between each twin and additionally by matching on 12 molecular genetic markers. Additional details on how the biological markers were obtained have been described elsewhere (Harris et al., 2006).

Sibling type. The genetic relatedness of individuals who were part of the same family was determined through selfreported answers to an in-school survey that asked participants to identify the individuals in their family with whom they lived (Harris et al., 2006; 2013). We excluded pairs of individuals who were unrelated (e.g., foster siblings) to other individuals in the same household.

Sex. Participants' self-reported sex was used as well.

\section{Twin and Sibling Pairs}

For the present study, twin pairs were divided into five groups based on sex and zygosity; MZ males (MZM), MZ females (MZF), DZ males (DZM), DZ females (DZF), and opposite-sex DZ twins (DZO). Then, additional subgroups for the sibling pairs were created based on whether the sibling pairs were full- or half-siblings, and based on their gender. The additional six subgroups included full-sibling males (FSM), full-sibling females (FSF), full-siblings of the 
opposite sex (FSO), half-sibling males (HSM), half-sibling females (HSF), and half-siblings of the opposite sex (HSO). Due to the design of the Add Health study, pairs of twins and siblings in the sample lived in the same household at the time of the survey (Harris et al., 2006). However, it was not possible to distinguish how long half-siblings had cohabited or whether pairs of half-siblings were related through their mothers or through their fathers because more detailed questions regarding how pairs of siblings were related to each other were not part of the survey.

\section{Age Groups}

Three age groups were created that span three developmental periods: adolescence (ages 12-17), young adulthood (ages 18-25), and adulthood (ages 26-33). To be included in an age group, both individuals belonging to a twin or sibling pair had to be within the age range specified. If an individual participant fell within the age ranges but had a sibling who was not within that age range, neither one was included in the analyses.

\section{Analysis Plan}

The classical twin study examines the similarity in the variance of a phenotype between MZ and DZ twins. MZ twins share $100 \%$ of their segregating genes, while DZ twins share, on average, $50 \%$. Three sources of phenotypic variance can be estimated by examining the similarities between pairs of twins: additive genetic $\left(\mathrm{a}^{2}\right)$, shared environment $\left(\mathrm{c}^{2}\right)$, and unique environment $\left(\mathrm{e}^{2}\right)$. Additive genetic sources include the effect of multiple genetic loci that act in an additive manner to influence the variance of a phenotype. The shared environment is thought to include aspects of the environment common to both twins within a family that are considered to make twins more similar to each other. Unique environmental influences arise from factors not shared within families and are often due to individualspecific experiences.

In this study, we extended the classical twin study by including pairs of individuals from within the same family, who differed in their genetic relatedness. Full-siblings share on average $50 \%$ of their genes and half-siblings share $25 \%$ of their genes identical by descent. When reared together, twins and full-siblings share $100 \%$ of the rearing environment. For part of their life, individuals related to one another as half-siblings will have experienced different rearing environments. Our models accounted for the fact that half-siblings do not share $100 \%$ of their rearing environment by constraining the shared environment covariance to be no larger than 50\% (Figure 1, Panel A). Including, fulland half-siblings along with $\mathrm{MZ}$ and $\mathrm{DZ}$ twins creates contrasts and allows for estimates of the presence of a special twin environment $\left(\mathrm{t}^{2}\right)$ in addition to additive genetic $\left(\mathrm{a}^{2}\right)$, shared environmental $\left(\mathrm{c}^{2}\right)$, and unique environmental $\left(\mathrm{e}^{2}\right)$ influences on the phenotype of interest.
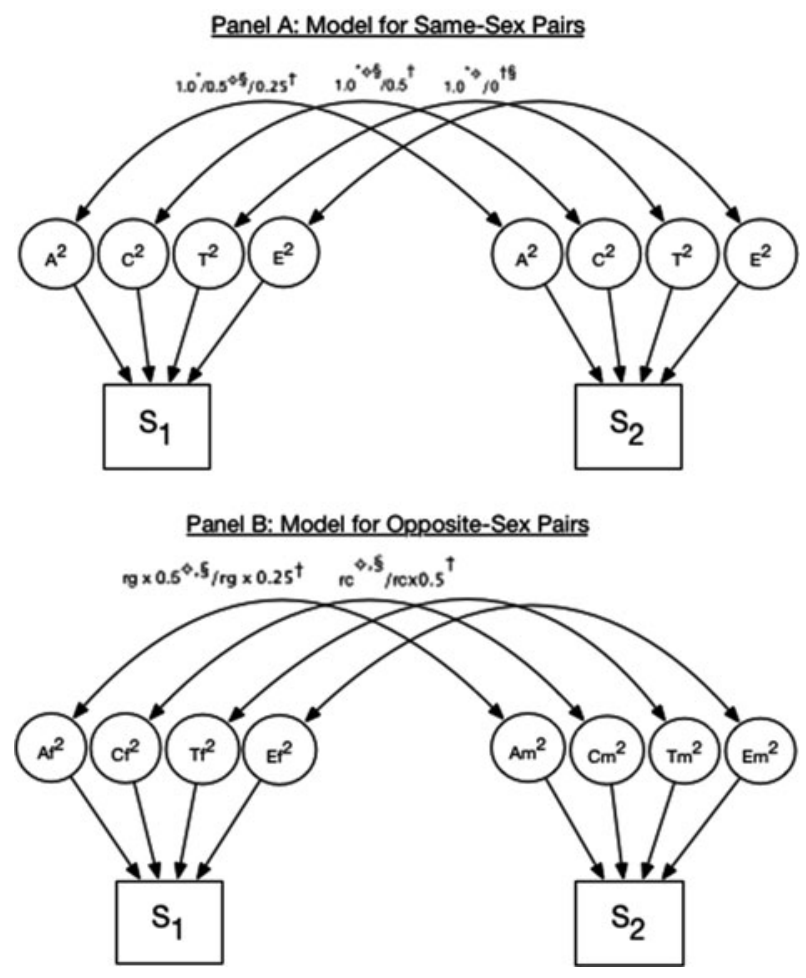

FIGURE 1

Conceptual ACTE model. Note: $\mathrm{S}_{1}=$ Sibling $1, \mathrm{~S}_{2}=$ Sibling 2 . $A^{2}=$ Additive genetic effects, $C^{2}=$ Shared environmental effects, $T^{2}=$ Special twin environmental effects, $E^{2}$ represents the effects of unique environment. The following model constraints are applied depending on sibling type: * $M Z$ pairs; $\ D Z$ pairs; $\S$ Full-sibling pairs; † Half-sibling pairs. A unique constraint $\left(r_{g}, r_{c}\right)$ is applied to opposite-sex pairs (depicted in Panel B).

\section{Genetic Model-Fitting}

Tetrachoric correlations for the binary cigarette use initiation variable were computed separately for twin and sibling pairs with complete data on the study variables (less than $2 \%$ of pairs of twins and siblings had missing data). Twin modeling assumptions that thresholds for cigarette use initiation could be equated across twin order, sibling order, zygosity, and sibling type, for males and females, were tested next.

To test the specific role of the special twin environment, age- and sex-specific univariate variance decomposition models adjusted for the age of each sibling pair were run for cigarette use initiation (Figure 1, Panel A). Constraints were added to each covariance depending on the type of sibling relationship. The genetic covariance was constrained to be 1.0 for MZ twins, 0.5 for DZ twins and full-siblings, and 0.25 for half-siblings. We constrained the shared environment covariance to 1.0 for all twin pairs and full-siblings. However, for the half-siblings, the shared environment covariance was constrained to be 0.5 . Lastly, the twin environment covariance was constrained to be 1.0 in twin pairs but it was set at zero for full- and half-siblings. 
TABLE 1

Participant Demographics (Mean [SD]/\%) by Genetic Relatedness and Age Group Genetic relatedness

\begin{tabular}{|c|c|c|c|c|c|c|}
\hline & All & Monozygotic & Dizygotic & Full-siblings & Half-siblings & \\
\hline & 12 - to 17 -year-olds & & & & & Sig. \\
\hline$n$ & 3,078 & 452 & 802 & 1,360 & 464 & - \\
\hline Sex (\% female) & $50.3 \%$ & $51.0 \%$ & $49.1 \%$ & $49.9 \%$ & $52.8 \%$ & ns \\
\hline Age & $15.6(1.4)$ & $15.8(1.3)$ & $15.7(1.4)$ & $15.7(1.4)$ & $15.4(1.6)$ & $<0.001$ \\
\hline Age difference* & $-0.06(1.8)$ & $0.01(0.2)$ & $0.00(0.1)$ & $-0.09(2.2)$ & $-0.14(2.6)$ & ns \\
\hline Cigarette use initiation & $44.6 \%$ & $40.0 \%$ & $41.4 \%$ & $45.4 \%$ & $51.9 \%$ & 0.001 \\
\hline \multirow[t]{2}{*}{ Unique families } & $97.7 \%$ & $99.1 \%$ & $100.0 \%$ & $97.2 \%$ & $94.0 \%$ & $<0.0001$ \\
\hline & 18- to 25-year-olds & & & & & \\
\hline$n$ & 3,264 & 490 & 822 & 1,490 & 462 & - \\
\hline Sex (\% female) & $50.9 \%$ & $53.5 \%$ & $47.5 \%$ & $51.7 \%$ & $51.7 \%$ & ns \\
\hline Age & $22.4(1.7)$ & $22.6(1.6)$ & $22.5(1.6)$ & $22.5(1.7)$ & 22.0 (1.9) & $<0.0001$ \\
\hline Age difference* & $-0.03(2.0)$ & $0.01(0.2)$ & $0.00(0.1)$ & $-0.08(2.4)$ & $0.05(3.0)$ & ns \\
\hline Cigarette use initiation & $81.5 \%$ & $81.7 \%$ & $81.5 \%$ & $81.1 \%$ & $82.9 \%$ & ns \\
\hline \multirow[t]{2}{*}{ Unique families } & $97.9 \%$ & $99.2 \%$ & $100.0 \%$ & $97.6 \%$ & $93.5 \%$ & $<0.0001$ \\
\hline & 26- to 33-year-olds & & & & & \\
\hline$n$ & 2,916 & 440 & 736 & 1,342 & 398 & - \\
\hline Sex (\% female) & $51.9 \%$ & $53.8 \%$ & $49.1 \%$ & $51.6 \%$ & $56.0 \%$ & ns \\
\hline Age & $29.1(1.6)$ & $29.2(1.5)$ & $28.9(1.6)$ & $29.1(1.6)$ & $28.9(1.8)$ & $<0.01$ \\
\hline Age difference* & $-0.01(1.9)$ & $0.00(0.1)$ & $0.00(0.1)$ & $-0.05(2.3)$ & $0.06(2.9)$ & Ns \\
\hline Cigarette use initiation & $82.6 \%$ & $78.8 \%$ & $82.8 \%$ & $82.8 \%$ & $85.2 \%$ & ns \\
\hline Unique families & $98.4 \%$ & $99.6 \%$ & $100.0 \%$ & $97.6 \%$ & $97.0 \%$ & $<0.0001$ \\
\hline
\end{tabular}

Note: *Difference in age between siblings in the same family.

We tested for two types of sex differences: qualitative and quantitative sex differences. Qualitative sex differences refer to the possibility that genetic effects influence a phenotype in one sex but not in the other sex. We tested for qualitative sex differences by constraining additive genetic, shared environment, special twin environment, and unique environment parameters to be equal across males and females and observing changes to model fit. Quantitative sex differences, however, refer to factors that have a stronger influence in one sex than the other. To test for quantitative sex differences, twin models constrain the genetic correlation, $r_{g}$, to be 1.0 (see Figure 1, Panel B) and the correlation between shared environments, $r_{c}$, to be 1.0 in opposite sex twin and sibling pairs, and examine changes to the fit of the model.

The first model run, Model 1, was a model where parameter estimates for additive genetic $\left(\mathrm{a}^{2}\right)$, shared environment $\left(\mathrm{c}^{2}\right)$, special twin environment $\left(\mathrm{t}^{2}\right)$, and unique environment $\left(\mathrm{e}^{2}\right)$ were estimated for the five twin zygosity groups (MZF, MZM, DZF, DZM, and DZO) and the six sibling groups (FSF, FSM, FSO, HSF, HSM, and HSO) with the genetic correlation $\left(r_{g}\right)$ and shared environment $\left(r_{c}\right)$ correlation freely estimated.

At each age group, the full model included agemoderated paths and age-moderated thresholds for cigarette use initiation. The influence of age moderation on the paths was tested (Model 2), as well as the influence of age-moderation on the threshold for cigarette initiation (Model 3). Next, differences in whether the same set of genes (Model 4) and the same set of shared environment influences (Model 5) influenced males and females to the same degree was tested. The next model tested quantitative sex differences (Model 6). Lastly, the significance of each parameter estimate was tested in Models 7 through 10 by removing it from the model and examining changes in model fit through chi-square tests.

\section{Results}

Participants for this study included 3,078 12- to 17-yearolds twins $(n=1,254)$ and siblings $(n=1,824) ; 3,26418$ to 25 -year-old twins $(n=1,312)$ and siblings $(n=1,952)$; and 2,916 26- to 33-year-old twins $(n=1,176)$ and siblings $(n=1,740)$. About half of the sample at each age group was female (see Table 1). The prevalence of having ever used a cigarette was $44.6 \%$ for the 12 - to 17 -year-old group overall, and a significant difference was observed in cigarette use prevalence by sibling type such that half-siblings had the highest prevalence (51.9\%) and MZ twins the lowest (40.0\%; see Table 1).

Because multiple pairs of twins and siblings were allowed to come from the same family (e.g., a pair of MZ twins and a pair of full-siblings living in the same household), we examined the number of times that each family was duplicated. In each age group, over $97 \%$ of the pairs in the sample were unique, in that each family contributed only one pair. Only a small proportion of participants came from families that contributed multiple pairs to the sample. Less than $3 \%$ of pairs across each age group came from families that had more than one pair from the same family. Significant differences by genetic relatedness were observed in the proportion of families that were duplicated. A greater proportion of half-siblings than full-siblings or twins came from families that were included in the sample multiple times.

\section{Twin Correlations}

The tetrachoric correlations for cigarette use initiation by age group, sex, and sibling type are presented in Table 2 and 


\section{TABLE 2}

Tetrachoric Correlations $(95 \% \mathrm{Cl})$

\begin{tabular}{|c|c|c|c|}
\hline & \multicolumn{2}{|c|}{ Cigarette use initiation } & \multirow[b]{2}{*}{$n$} \\
\hline & Correlations & $95 \% \mathrm{Cl}$ & \\
\hline \multicolumn{4}{|c|}{12 - to 17 -year-olds ( $n=1,539$ pairs) } \\
\hline MZF & 0.68 & $(0.58,0.77)$ & 116 \\
\hline MZM & 0.57 & $(0.45,0.69)$ & 110 \\
\hline DZF & 0.67 & $(0.57,0.76)$ & 117 \\
\hline DZM & 0.57 & $(0.46,0.68)$ & 123 \\
\hline DZO & 0.25 & $(0.13,0.38$ & 161 \\
\hline FSF & 0.60 & $(0.51,0.68)$ & 194 \\
\hline FSM & 0.44 & $(0.34,0.54)$ & 195 \\
\hline FSO & 0.20 & $(0.11,0.29)$ & 291 \\
\hline HSF & 0.37 & $(0.20,0.55)$ & 66 \\
\hline HSM & 0.42 & $(0.23,0.61)$ & 52 \\
\hline HSO & 0.27 & $(0.13,0.41)$ & 114 \\
\hline \multicolumn{4}{|c|}{ 18- to 25 -year-olds ( $n=1,629$ pairs) } \\
\hline MZF & 0.73 & $(0.63,0.83)$ & 131 \\
\hline MZM & 0.82 & $(0.73,0.90)$ & 113 \\
\hline DZF & 0.48 & $(0.34,0.63)$ & 109 \\
\hline DZM & 0.27 & $(0.09,0.45)$ & 129 \\
\hline DZO & 0.29 & $(0.14,0.43)$ & 171 \\
\hline FSF & 0.40 & $(0.29,0.51)$ & 228 \\
\hline FSM & 0.44 & $(0.33,0.56)$ & 204 \\
\hline FSO & 0.41 & $(0.31,0.52)$ & 313 \\
\hline HSF & 0.37 & $(0.18,0.56)$ & 68 \\
\hline HSM & 0.41 & $(0.13,0.70)$ & 58 \\
\hline $\mathrm{HSO}$ & -0.02 & $(-0.31,0.27)$ & 105 \\
\hline \multicolumn{4}{|c|}{26 - to 33 -year-olds ( $n=1,438$ pairs) } \\
\hline MZF & 0.81 & $(0.73,0.90)$ & 114 \\
\hline MZM & 0.88 & $(0.81,0.94)$ & 96 \\
\hline DZF & 0.46 & $(0.31,0.61)$ & 103 \\
\hline DZM & 0.57 & $(0.41,0.74)$ & 107 \\
\hline DZO & 0.42 & $(0.27,0.57)$ & 148 \\
\hline FSF & 0.53 & $(0.42,0.63)$ & 206 \\
\hline FSM & 0.39 & $(0.25,0.53)$ & 189 \\
\hline FSO & 0.35 & $(0.23,0.47)$ & 276 \\
\hline HSF & 0.50 & $(0.31,0.68)$ & 62 \\
\hline HSM & 0.54 & $(0.19,0.90)$ & 37 \\
\hline HSO & 0.07 & $(-0.23,0.37)$ & 100 \\
\hline
\end{tabular}

are discussed first by comparing the correlations across zygosity and siblings. The MZ and DZ correlations were similar for the 12- to 17-year-old group, suggesting shared environmental influences. The MZ correlation exceeded the $\mathrm{DZ}$ correlation in the two oldest age groups (18- to 25-year-olds and 26- to 33-year-olds), likely suggesting that genetic factors contribute to variation in cigarette use initiation. Comparing correlations between twins and siblings, we found that the DZ correlation was slightly higher than the sibling correlations in the youngest (12- to 17-year-old) group, possibly suggesting the influence of the special twin environment. In the 18- to 25-year-old group as well as in the oldest (26- to 33-year-old) group, the correlations between the $\mathrm{DZ}$ and sibling groups were similar and did not suggest the presence of a special twin environment.

\section{Twin Model Assumptions}

We next tested twin model assumptions (Table 3 ) that the thresholds for the binary cigarette use variable could be equated for each member of pairs of twins and siblings to test the effect of twin and sibling order, across sibling type (twin vs. siblings), as well as across same- and opposite-sex pairs, and males and females. In the 12- to 17- and 18- to 25-year-old groups, the thresholds could be equated across twin and sibling order, across sibling type, and across males and females in twin pairs. However, in the 18- to 25-yearold group, the thresholds could not be equated across samesex and opposite-sex pairs or across males and females in sibling pairs. In the 26- to 33-year-olds, thresholds could not be equated across sibling order in sibling pairs, across same-sex and opposite-sex pairs, or across males and females in sibling pairs. Given these results, subsequent models included for all age groups separate thresholds for males and females within each zygosity and sibling group. In addition, we included each individual's age as a covariate on both the thresholds and parameter estimates in the variance decomposition models.

\section{Genetic Models}

Table 4 presents the fit statistics for each of the age-specific, variance decomposition models that were carried out for cigarette use initiation. At each age group, the full model included age-moderated, sex-specific, and sibling-specific paths, and thresholds for cigarette use initiation (Table 4, Model 1). We tested the influence of the age-moderated paths by removing them from the full model. The resulting change in model fit was not significant in any of the age groups. We then tested the effect of removing the age moderation on the threshold, which significantly reduced model fit (Model 2) in the 12- to 17-year-old and the 18- to 25year-old groups (12- to 17-year-olds $\chi^{2}=8.34, p=.004$; 18 - to 25 -year-olds $\left.\chi^{2}=5.09, p=.024\right)$. Subsequent models included the age-moderated threshold for the 12- to 17and 18- to 25-year-old age groups. However, in the 26- to 33-year-old group, removal of the age-moderated paths or the age-moderated thresholds did not significantly reduce the fit of the model $\left(\chi^{2}=2.11, p=n s\right)$, suggesting that for the adult group of twins and siblings, age did not significantly influence the thresholds of cigarette use or path estimates. Therefore, the age moderation was not included in subsequent models for the 26- to 33-year-olds.

Next, we tested whether the same set of genes (Model 4) had the same influence on cigarette use initiation across males and females (qualitative sex differences) by setting the genetic correlation $\left(r_{g}\right)$ to 1 . In Model 5 , we tested whether the same set of familial experiences influenced initiation of cigarettes in males and females by constraining the shared environmental correlation $\left(r_{c}\right)$ to 1 . Across each of the three age groups, the genetic correlation $\left(r_{\mathrm{g}}\right)$ was constrained to 1 without observing reductions in model fit. Only in the 12- to 17-year-old group was a significant deterioration in model fit found when both the genetic and shared environmental correlation were constrained to be 1.0 (Model 5: $\left.\chi^{2}=4.10, p=.040\right)$. Subsequent models for the 12- to 17-year old group included a constraint that $r_{g}$ was estimated at 1 and $r_{c}$ was allowed to be freely estimated. In the two older age groups, both $r_{g}$ and $r_{c}$ were constrained to be 1 in subsequent models. Constraining the parameter 
TABLE 3

Testing Twin Model Assumptions by Age Group for Cigarette use Initiation

\begin{tabular}{|c|c|c|c|c|c|c|c|}
\hline & $\begin{array}{c}\text { Estimated } \\
\text { Parameters }\end{array}$ & $-2 \mathrm{LL}$ & df & $\mathrm{AIC}$ & $\Delta \mathrm{LL}$ & $\Delta d f$ & $p$ \\
\hline \multicolumn{8}{|l|}{ 12- to 17 -year-old group ( $n=1,539$ pairs) } \\
\hline 1. Saturated model & 33 & 4039.9 & 3045 & -2050.10 & - & - & - \\
\hline 2. Equal thresholds across sibling order in twins & 28 & 4044.9 & 3050 & -2055.14 & 4.96 & 5 & .42 \\
\hline 3. Equal thresholds across sibling order in siblings & 27 & 4044.0 & 3051 & -2058.04 & 4.06 & 6 & .67 \\
\hline 4. Equal thresholds across sibling order in twins and siblings & 22 & 4048.9 & 3056 & -2063.08 & 9.02 & 11 & .62 \\
\hline 5. Equal thresholds across zygosity (MZ vs. DZ) & 20 & 4053.3 & 3058 & -2062.65 & 4.43 & 2 & .11 \\
\hline 7. Equal thresholds across relationship type (MZ/DZ vs. siblings) & 16 & 4059.2 & 3062 & -2064.78 & 10.30 & 6 & .11 \\
\hline 8. Equal thresholds across SS \& OS & 15 & 4063.1 & 3063 & -2062.94 & 14.14 & 7 & .05 \\
\hline 9. Equal thresholds across $\mathrm{f} / \mathrm{m}$ sex in twins & 19 & 4053.5 & 3059 & -2064.51 & 4.58 & 3 & .21 \\
\hline 10. Equal thresholds across $\mathrm{f} / \mathrm{m}$ sex in siblings & 19 & 4053.5 & 3059 & -2064.53 & 4.55 & 3 & .21 \\
\hline \multicolumn{8}{|l|}{ 18- to 25 -year-old group ( $n=1,629$ pairs) } \\
\hline 1. Saturated model & 33 & 2988.6 & 3200 & -3411.38 & - & - & - \\
\hline 2. Equal thresholds across sibling order in twins & 28 & 2994.0 & 3205 & -3416.02 & 5.36 & 5 & .37 \\
\hline 3. Equal thresholds across sibling order in siblings & 27 & 2997.4 & 3206 & -3414.57 & 8.81 & 6 & .18 \\
\hline 6. Equal thresholds across sibling type (Full- vs. half-siblings) & 20 & 3008.7 & 3213 & -3417.33 & 5.88 & 2 & .05 \\
\hline 7. Equal thresholds across relationship type (MZ/DZ vs. siblings) & 16 & 3012.1 & 3217 & -3421.95 & 9.26 & 6 & .16 \\
\hline 8. Equal thresholds across SS and OS & 15 & 3020.8 & 3218 & -3415.20 & 18.01 & 7 & .01 \\
\hline 9. Equal thresholds across $\mathrm{f} / \mathrm{m}$ sex in twins & 19 & 3006.4 & 3214 & -3421.59 & 3.62 & 3 & .31 \\
\hline 10. Equal thresholds across $\mathrm{f} / \mathrm{m}$ sex in siblings & 19 & 3011.6 & 3214 & -3416.39 & 8.82 & 3 & .03 \\
\hline \multicolumn{8}{|l|}{ 26- to 33-year-old group ( $n=1,438$ pairs) } \\
\hline 1. Saturated model & 33 & 2495.6 & 2843 & -3190.43 & - & - & - \\
\hline 2. Equal thresholds across sibling order in twins & 28 & 2503.7 & 2848 & -3192.34 & 8.09 & 5 & .15 \\
\hline 3. Equal thresholds across sibling order in siblings & 27 & 2509.7 & 2849 & -3188.30 & 14.13 & 6 & .03 \\
\hline 4. Equal thresholds across sibling order in twins and siblings & 22 & 2517.8 & 2854 & -3190.21 & 22.22 & 11 & .02 \\
\hline 5. Equal thresholds across zygosity (MZ vs. DZ) & 20 & 2522.8 & 2856 & -3189.24 & 4.97 & 2 & .08 \\
\hline 6. Equal thresholds across sibling type (Full- vs. half-siblings) & 20 & 2520.9 & 2856 & -3191.05 & 3.15 & 2 & .21 \\
\hline 7. Equal thresholds across relationship type (MZ/DZ vs. siblings) & 16 & 2526.9 & 2860 & -3193.08 & 9.13 & 6 & .17 \\
\hline 8. Equal thresholds across SS \& OS & 15 & 2534.9 & 2861 & -3187.08 & 17.12 & 7 & .02 \\
\hline 9. Equal thresholds across $\mathrm{f} / \mathrm{m}$ sex in twins & 19 & 2524.3 & 2857 & -3189.73 & 6.48 & 3 & .09 \\
\hline 10. Equal thresholds across $\mathrm{f} / \mathrm{m}$ sex in siblings & 19 & 2529.2 & 2857 & -3184.80 & 11.41 & 3 & .01 \\
\hline
\end{tabular}

estimates $\left(\mathrm{a}^{2}, \mathrm{c}^{2}, \mathrm{t}^{2}\right.$, and $\left.\mathrm{e}^{2}\right)$ to be equal for males and females did not deteriorate the fit of the models in any age groups (Model 6).

Lastly, the individual effect of each parameter estimate on explaining variance in cigarette use initiation was tested in Models 7 through 10. Removing the influence of the shared environment on cigarette use initiation in the 12- to 17-year-olds (Model 8) resulted in a reduction in the fit of the model $\left(\chi^{2}=20.98, p<.0001\right)$, as did removing the influence of both the shared and special twin environments simultaneously (Model 10: $\chi^{2}=21.02, p<.0001$ ). Removing the additive genetic influence from the models resulted in worse model fit for the 18- to 25-year-olds (Model 10: $\chi^{2}$ $=11.23, p<.0001$ ) and the 26 - to 33-year-olds (Model 10: $\chi^{2}=9.75, p<.0001$, respectively). Removing the shared environment or the special twin environment did not deteriorate the fit of the models in the three age groups.

\section{Variance Components}

For each age group, we derived variance components from the best fitting model that included all four variance components. We present the results in Table 5 and discuss them below separately for each age group.

12- to 17-year-olds. In the case of the youngest age group, the best fitting model indicated that additive genetic factors accounted for $11.5 \%$ (95\% CI [0\%, 47\%]) of the variance in cigarette use initiation. In this group, the shared environment accounted for the most variance in cigarette use initiation, $44.4 \%$ (95\% CI [24\%, 59\%]), and the special twin environment accounted for $6.8 \%(95 \%$ CI $[0 \%, 23 \%])$ of the variance. Unique environmental influences accounted for $37.2 \%(95 \%$ CI $[25 \%, 51 \%])$ of the variance in 12 - to 17 year-olds.

18- to 25-year-olds. The derived variance component for the 18- to 25-year-olds came from a model in which parameter estimates were allowed to be equal across sex. Additive genetic factors accounted for $68.8 \%$ (95\% CI [31\%, 85\%]) of the variance in cigarette use initiation among 18 - to $25-$ year-olds, and the shared environment accounted for $6.4 \%$ (95\% CI $[0 \%, 28 \%])$ of the variance. The special twin environment did not account for any $(0 \% ; 95 \%$ CI $[0 \%, 16 \%])$ variance in this age group, while the unique environment accounted for $24.8 \%$ (95\% CI [14\%, 41\%]) of the variance in cigarette use initiation.

26- to 33-year-olds. Estimates of the variance components derived from the best fitting model in the 26- to 33year-old age group indicated that additive genetic factors accounted for $65.6 \%$ (95\% CI [25\%, 91\%]) of the variance, while shared environmental factors accounted for $11.6 \%$ 
TABLE 4

ACTE Univariate Models of Cigarette use Initiation by Age Group

\begin{tabular}{|c|c|c|c|c|c|c|c|}
\hline & $\begin{array}{l}\text { Estimated } \\
\text { parameters }\end{array}$ & $-2 \mathrm{LL}$ & $d f$ & AIC & $\Delta \mathrm{LL}$ & $\Delta d f$ & $p$ value \\
\hline \multicolumn{8}{|l|}{ 12- to 17 -year-old group ( $n=1,539$ pairs) } \\
\hline 1.Moderated ACTE model $\mathrm{w} / \mathrm{r}_{\mathrm{g}}$ and $\mathrm{r}_{\mathrm{c}}$ & 27 & 4038.73 & 3051 & -2063.27 & - & - & - \\
\hline 2. ACTE w/o moderated paths & 19 & 4049.93 & 3059 & -2068.07 & 5.89 & 8 & .660 \\
\hline 3. ACTE w/o moderated paths or thresholds & 18 & 4058.27 & 3060 & -2061.73 & 8.34 & 1 & .004 \\
\hline 4. Test qualitative sex diff. in ACTE & 18 & 4049.93 & 3060 & -2070.07 & 0.00 & 1 & 1.000 \\
\hline 5. Constrain $r_{c}$ and $r_{g}$ & 17 & 4054.04 & 3061 & -2067.96 & 4.10 & 1 & .040 \\
\hline 6. Testing quantitative sex diff. in ACTE & 14 & 4052.72 & 3064 & -2075.28 & 2.79 & 4 & .590 \\
\hline 7. CTE model & 13 & 4053.09 & 3065 & -2076.91 & 0.38 & 1 & .540 \\
\hline 8. ATE model & 13 & 4073.70 & 3065 & -2056.30 & 20.98 & 1 & .000 \\
\hline 9. ACE model & 13 & 4053.36 & 3065 & -2076.64 & 0.64 & 1 & .420 \\
\hline 10. AE model & 12 & 4073.74 & 3066 & -2058.26 & 21.02 & 2 & .000 \\
\hline \multicolumn{8}{|l|}{ 18- to 25 -year-olds ( $n=1,629$ pairs) } \\
\hline 1.Moderated ACTE model $\mathrm{w} / \mathrm{r}_{\mathrm{g}}$ and $\mathrm{r}_{\mathrm{c}}$ & 27 & 2998.29 & 3202 & -3405.71 & - & - & - \\
\hline 2. ACTE w/o moderated paths & 19 & 3005.52 & 3210 & -3414.48 & 7.23 & 8 & .512 \\
\hline 3. ACTE w/o moderated paths or thresholds & 18 & 3010.61 & 3211 & -3411.39 & 5.09 & 1 & .024 \\
\hline 4. Test qualitative sex diff. in ACTE & 18 & 3005.52 & 3211 & -3416.48 & 0.00 & 1 & 1.000 \\
\hline 5. Constrain $r_{\mathrm{c}}$ and $r_{\mathrm{g}}$ & 17 & 3005.52 & 3212 & -3418.48 & 0.00 & 1 & 1.000 \\
\hline 6. Testing quantitative sex diff. in ACTE & 13 & 3007.67 & 3216 & -3424.33 & 2.15 & 4 & .710 \\
\hline 7. CTE model & 12 & 3018.9 & 3217 & -3415.10 & 11.23 & 1 & .000 \\
\hline 8. ATE model & 12 & 3008.02 & 3217 & -3425.98 & 0.34 & 1 & .560 \\
\hline 9. ACE model & 12 & 3007.67 & 3217 & -3426.33 & 0.00 & 1 & 1.000 \\
\hline 10. AE model & 11 & 3008.02 & 3218 & -3427.98 & 0.34 & 2 & .840 \\
\hline \multicolumn{8}{|l|}{26 - to 33-year-olds ( $n=1,440$ pairs) } \\
\hline 1.Moderated ACTE model $w / r_{g} \& r_{c}$ & 27 & 2524.20 & 2849 & -3173.80 & - & - & - \\
\hline 2. ACTE w/o moderated paths & 19 & 2524.49 & 2857 & -3189.51 & 0.30 & 8 & 1.000 \\
\hline 3. ACTE w/o moderated paths or thresholds & 18 & 2526.61 & 2858 & -3189.39 & 2.11 & 1 & .146 \\
\hline 4. Test qualitative sex diff. in ACTE & 17 & 2526.61 & 2859 & -3191.39 & 0.00 & 1 & 1.000 \\
\hline 5. Constrain $r_{c}$ and $r_{g}$ & 16 & 2526.86 & 2860 & -3193.14 & 0.26 & 1 & .610 \\
\hline 6. Testing quantitative sex diff. in ACTE & 12 & 2528.94 & 2864 & -3199.06 & 2.34 & 5 & .800 \\
\hline 7. CTE model & 11 & 2538.69 & 2865 & -3191.31 & 9.75 & 1 & .000 \\
\hline 8. ATE model & 11 & 2529.96 & 2865 & -3200.04 & 1.02 & 1 & .310 \\
\hline 9. ACE model & 11 & 2529.15 & 2865 & -3200.85 & 0.21 & 1 & .650 \\
\hline 10. AE model & 10 & 2529.99 & 2866 & -3202.01 & 1.05 & 2 & .590 \\
\hline
\end{tabular}

Note: Bold type indicates best-fitting model that included all four variance components.

\section{TABLE 5}

Variance Components for Cigarette use Initiation in ACTE Models by Age Group

\begin{tabular}{|c|c|c|c|c|c|c|c|c|}
\hline \multirow{3}{*}{$\begin{array}{l}12 \text { - to } 17 \text {-year-olds } \\
18 \text { - to } 25 \text {-year-olds }\end{array}$} & \multicolumn{2}{|c|}{ Additive genetic } & \multicolumn{2}{|c|}{$\begin{array}{l}\text { Shared } \\
\text { environment }\end{array}$} & \multicolumn{2}{|c|}{ Twin environment } & \multicolumn{2}{|c|}{ Unique environment } \\
\hline & $11.5 \%$ & {$[0 \%, 47 \%]$} & $44.4 \%$ & {$[24 \%, 59 \%]$} & $6.8 \%$ & {$[0 \%, 23 \%]$} & $37.2 \%$ & {$[25 \%, 51 \%]$} \\
\hline & $68.8 \%$ & {$[31 \%, 85 \%]$} & $6.4 \%$ & {$[0 \%, 28 \%]$} & $0.0 \%$ & {$[0 \%, 16 \%]$} & $24.8 \%$ & {$[14 \%, 41 \%]$} \\
\hline 26- to 33-year-olds & $65.6 \%$ & {$[25 \%, 91 \%]$} & $11.6 \%$ & {$[0 \%, 34 \%]$} & $5.0 \%$ & {$[0 \%, 25 \%]$} & $17.7 \%$ & {$[9 \%, 32 \%]$} \\
\hline
\end{tabular}

(95\% CI $[0 \%, 34 \%])$. The special twin environment accounted for $5 \%(95 \%$ CI $[0 \%, 25 \%])$ of the variance in cigarette use initiation. The unique environment accounted for $17.7 \%$ (95\% CI [9\%, 32\%]) of the cigarette use initiation variance.

\section{Discussion}

In an effort to understand the role of the special twin environment that is shared between twin siblings on initiating cigarette use, the present study tested the contribution of additive genetic, shared, and special twin environmental factors by examining similarities in cigarette use initiation among MZ, DZ, full-, and half-sibling pairs. In our sample, half-siblings in each of the three age groups reported higher rates of cigarette use initiation than other pairs of individ- uals. The higher rate of cigarette use among pairs of halfsiblings is consistent with previous work, indicating that half-siblings in blended families have higher rates of externalizing problems, including substance use (Kendler et al., 2012) and criminal behavior (Kendler et al., 2015). Studies of the emotional wellbeing and adjustment of children and adolescents who experience changes in family structure reveals that externalizing problems might be due to receiving lower levels of parental emotional availability, experiencing multiple family transitions in family structure, or living in home environments characterized by parental discord (Marcynyszyn et al., 2008; Soloski \& Berryhill, 2016). Such family stressors extend to initiating substances use in adolescence as well (Gutman et al., 2011).

Our results regarding how additive genetic and shared environment factors contribute to the initiation of cigarette 
use is consistent with previous work with this population. Although $11.5 \%$ of the variance in cigarette use initiation is due to additive genetic factors, the confidence intervals included zero, suggesting a non-significant effect. In the youngest group, about half of the variance in cigarette initiation was accounted for by the shared environment. The finding that shared environmental factors contribute more to the variance in cigarette use initiation than additive genetic factors in adolescence has been previously reported in studies using various adolescent twin samples (Bares et al., 2015; Do et al., 2015; Maes et al., 2016; Unger et al., 2011). In addition, the shared environment has been found to decrease while the influence of additive genetic factors increases as individuals move from adolescence into adulthood (Bares et al., 2015; Öncel et al., 2014). In fact, while the shared environment explains slightly less than half of the variance in cigarette use initiation in adolescence, this decreases in the 18- to 25-year-olds and 26- to 33-year-olds. We suspect that the decrease observed in the contribution of the shared environment comes about because as individuals progress past the initiation of stage of cigarette use, genes involved in metabolizing nicotine begin to shape and influence future cigarette use behaviors and therefore play a more critical role. We found that more than $60 \%$ of the variance in cigarette use initiation was explained by additive genetic factors in the two oldest age groups, in line with previous reports (Sullivan \& Kendler, 1999).

Because we conceptualized that the special twin environment as part of the shared environment that twins experience within a family, we had expected that the effect of being a twin would decrease as individuals aged into young adulthood and beyond. Our findings did not support our predictions that the effect of the special twin environment would be stronger during adolescence. In fact, the special twin environment did not contribute significantly to the variance in cigarette initiation in any age group. Without a direct measure of the length of cohabitation between half-siblings, we might be underestimating the effect of the special twin environment for initiating cigarette use. Theories and studies of friendship selection (Kandel, 1978) suggest that individuals are actively involved in creating their own social environment and, as a result, adolescent twins may be choosing to include their co-twin in their social group (Rose, 2002) and, as a unit, may also choose friends who have similar views as themselves (Rushton \& Bons, 2005). As a result of including similar others in their social environment, the drug use of one twin may influence the initiation and use of drugs by the co-twin. These social processes may be most relevant during adolescence, a time when individuals are most at risk for the influence of peers and friends to initiate drugs. Adolescent twins may be bringing shared friends who hold similar views on substance use to the social milieu they have created with their co-twin, and together they may all develop more similar behaviors to one another, including drug use. However, with our current sample we could not confidently detect these influences. Future studies of adolescent twins and siblings may need to take into account how much contact twins and siblings have had with one another to make confident conclusions regarding the role that the special twin environment plays.

Our findings, should be considered with the following limitations in mind. While the survey asked participants to list the members of their family with whom they currently lived allowing us to include pairs of siblings who were currently living together, we do not have information about the length of time that pairs of individuals lived together. Despite not having a direct measure of the time that halfsiblings had lived together, we accounted for the different rearing environment that half-siblings likely experience by constraining the shared environment for half-siblings to be $50 \%$. A second limitation of our study has to do with the small sample size in each of the sibling groups; in particular, the half-siblings part of the Add Health study that could have contributed to the wide confidence intervals. Lastly, although previous work suggests that there exist racial and/or ethnic differences in the degree to which genetic and shared environmental factors contribute to cigarette use (Bares et al., 2016), the small number of African-American twins and siblings available in the sample prevented us from testing both the influence of $\mathrm{t}^{2}$ and racial/ethnic differences simultaneously.

Notwithstanding these limitations, we have observed that shared environmental influences that are not specific to being a twin explain a large proportion of the cigarette initiation variance in adolescence. Additive genetic effects appear after age 18 and remain strong into adulthood. Continuing to unpack aspects of the shared environment that influence cigarette use initiation is useful when we consider just how important familial risk factors and familial experiences are in initiation of cigarettes and other substances in adolescence.

\section{Acknowledgments}

This research uses data from Add Health, a program project directed by Kathleen Mullan Harris and designed by J. Richard Udry, Peter S. Bearman, and Kathleen Mullan Harris at the University of North Carolina at Chapel Hill and funded by grant P01-HD31921 from the Eunice Kennedy Shriver National Institute of Child Health and Human Development, with cooperative funding from 23 other federal agencies and foundations. Special acknowledgment is due to Ronald R. Rindfuss and Barbara Entwisle for assistance in the original design. Information on how to obtain the Add Health data files is available on the Add Health website (http://www.cpc.unc.edu/addhealth). No direct support was received from grant P01-HD31921 for this analysis. Research reported in this manuscript was supported by the National Institute on Drug Abuse of the National 
Institutes of Health under award number K01DA036681 (Bares).

\section{Conflict of Interest}

None.

\section{Ethical Standards}

The authors assert that all procedures contributing to this work comply with the ethical standards of the relevant national and institutional committees on human experimentation and with the Helsinki Declaration of 1975, as revised in 2008 .

\section{References}

Avenevoli, S., \& Merikangas, K. R. (2003). Familial influences on adolescent smoking. Addiction, 98, 1-20.

Bares, C. B., Kendler, K. S., \& Maes, H. H. (2015). Developmental changes in genetic and shared environmental contributions to smoking initiation and subsequent smoking quantity in adolescence and young adulthood. Twin Research and Human Genetics, 18, 497-506.

Bares, C. B., Kendler, K. S., \& Maes, H. H. (2016). Racial differences in heritability of cigarette smoking in adolescents and young adults. Drug and Alcohol Dependence, 166, 75-84.

Bartels, M., Van den Oord, E., Hudziak, J., Rietveld, M., Van Beijsterveldt, C., \& Boomsma, D. (2004). Genetic and environmental mechanisms underlying stability and change in problem behaviors at ages $3,7,10$, and 12 . Developmental Psychology, 40, 852.

Bierut, L., Dinwiddie, S. H., Begleiter, H., Crowe, R. R., Hesselbrock, V., Nurnberger, J. I., ... Reich, T. (1998). Familial transmission of substance dependence: Alcohol, marijuana, cocaine, and habitual smoking: a report from the collaborative study on the genetics of alcoholism. Archives of General Psychiatry, 55, 982-988.

Bricker, J. B., Peterson, A. V., Andersen, M. R., Leroux, B. G., Rajan, K. B., \& Sarason, I. G. (2006). Close friends', parents', and older siblings' smoking: Reevaluating their influence on children's smoking. Nicotine \& Tobacco Research, 8, 217 226.

Burt, S. A., Barnes, A. R., McGue, M., \& Iacono, W. G. (2008). Parental divorce and adolescent delinquency: Ruling out the impact of common genes. Developmental Psychology, 44, 1668-1667.

Burt, S. A., Krueger, R. F., McGue, M., \& Iacono, W. (2003). Parent-child conflict and the comorbidity among childhood externalizing disorders. Archives of General Psychiatry, 60, 505-513.

D’Onofrio, B. M., Turkheimer, E., Emery, R. E., Slutske, W. S., Heath, A. C., Madden, P. A., \& Martin, N. G. (2005). A genetically informed study of marital instability and its association with offspring psychopathology. Journal of Abnormal Psychology, 114, 570.

Do, E. K., Prom-Wormley, E. C., Eaves, L. J., Silberg, J. L., Miles, D. R., \& Maes, H. H. (2015). Genetic and environ- mental influences on smoking behavior across adolescence and young adulthood in the virginia twin study of adolescent behavioral development and the transitions to substance abuse follow-up. Twin Research and Human Genetics, 18, 43-51.

Gilman, S. E., Rende, R., Boergers, J., Abrams, D. B., Buka, S. L., Clark, M. A., ... Niaura, R. S. (2009). Parental smoking and adolescent smoking initiation: An intergenerational perspective on tobacco control. Pediatrics, 123, E274-E281.

Gutman, L. M., Eccles, J. S., Peck, S., \& Malanchuk, O. (2011). The influence of family relations on trajectories of cigarette and alcohol use from early to late adolescence. Journal of Adolescence, 34, 119-128.

Harris, K. M. (2013). The add health study: Design and accomplishments. Chapel Hill, NC: Carolina Population Center, University of North Carolina at Chapel Hill.

Harris, K. M., Halpern, C. T., Haberstick, B. C., \& Smolen, A. (2013). The national longitudinal study of adolescent health (add health) sibling Pairs data. Twin Research and Human Genetics, 16, 391-398.

Harris, K. M., Halpern, C. T., Smolen, A., \& Haberstick, B. C. (2006). The national longitudinal study of adolescent health (add health) twin data. Twin Research and Human Genetics, 9, 988-997.

Harris, K. M., Halpern, C. T., Whitsel, E., Hussey, J., Tabor, J., Enzel, P., \& Udry, J. R. (2009). The national longitudinal study of adolescent to adult health: Research design. Retrieved from http://www.cpc.unc.edu/projects/addhealth/ design

Johnston, L. D., O’Malley, P. M., Miech, R. A., Bachman, J. G., \& Schulenberg, J. (2015). Monitoring the future national results on adolescent drug use: Overview of key findings, 2014. Ann Arbor, MI: The University of Michigan Institute for Social Research. Retrieved from http://www.monitoringthefuture.org/pubs/monographs/ mtf-overview2014.pdf.

Johnston, L. D., O’Malley, P., Bachman, J. G., \& Schulenberg, J. (2013, December 18). Teen smoking continues to decline in 2013. Ann Arbor: University of Michigan News Service.

Kandel, D. B. (1978). Homophily, selection, and socialization in adolescent friendships. American Journal of Sociology, 84, 427-436.

Kendler, K. S., Lönn, S. L., Maes, H. H., Sundquist, J., \& Sundquist, K. (2015). The etiologic role of genetic and environmental factors in criminal behavior as determined from full- and half-sibling pairs: An evaluation of the validity of the twin method. Psychological Medicine, 45, 18731880.

Kendler, K. S., Sundquist, K., Ohlsson, H., Palmér, K., Maes, H. H., Winkleby, M. A., \& Sundquist, J. (2012). Genetic and familial environmental influences on the risk for drug abuse: A national Swedish adoption study. Archives of General Psychiatry, 69, 690-697.

Maes, H. H., Prom-Wormley, E., Eaves, L. J., Rhee, S. H., Hewitt, J. K., Young, S., ... Neale, M. C. (2016). A genetic epidemiological mega analysis of smoking initiation in 
adolescents. Nicotine \& Tobacco Research. Advance online publication. doi:10.1093/ntr/ntw294

Maes, H. H., Woodard, C. E., Murrelle, L., Meyer, J. M., Silberg, J. L., Hewitt, J. K., ... Eaves, L. J. (1999). Tobacco, alcohol and drug use in eight- to sixteen-year-old twins: The Virginia twin study of adolescent behavioral development. Journal of Studies on Alcohol, 60, 293-305.

Marcynyszyn, L. A., Evans, G. W., \& Eckenrode, J. (2008). Family instability during early and middle adolescence. Journal of Applied Developmental Psychology, 29, 380-392.

O'Loughlin, J., Karp, I., Koulis, T., Paradis, G., \& DiFranza, J. (2009). Determinants of first puff and daily cigarette smoking in adolescents. American Journal of Epidemiology, 170, 585-597.

Öncel, S. Y., Dick, D. M., Maes, H. H., \& Aliev, F. (2014). Risk factors influencing smoking behavior: A Turkish twin study. Twin Research and Human Genetics, 17, 563-573.

Rhee, S. H., Hewitt, J. K., Young, S. E., Corley, R. P., Crowley, T. J., \& Stallings, M. C. (2003). Genetic and environmental influences on substance initiation, use, and problem use in adolescents. Archives of general psychiatry, 60, 1256-1264.

Rohde, P., Lewinsohn, P. M., Brown, R. A., Gau, J. M., \& Kahler, C. W. (2003). Psychiatric disorders, familial factors and cigarette smoking: I. Associations with smoking initiation. Nicotine \& Tobacco Research, 5, 85-98.

Rose, R. J. (2002). How do adolescents select their friends? A behavior-genetic perspective. In L. Pulkkinen, A. Caspi, L. Pulkkinen \& A. Caspi (Eds.), Paths to successful development: Personality in the life course (pp. 106-125). New York, NY: Cambridge University Press.

Rushton, J. P., \& Bons, T. A. (2005). Mate choice and friendship in twins: Evidence for genetic similarity. Psychological Science, 16, 555-559.

Seglem, K. B., Waaktaar, T., Ask, H., \& Torgersen, S. (2015). Genetic and environmental influences on adolescents' smoking involvement: A multi-informant twin study. Behavior Genetics, 45, 171-180.

Slomkowski, C., Rende, R., Novak, S., Lloyd-Richardson, E., \& Niaura, R. (2005). Sibling effects on smoking in adolescence: Evidence for social influence from a genetically informative design. Addiction, 100, 430-438.

Soloski, K. L., \& Berryhill, M. B. (2016). Gender differences: Emotional distress as an indirect effect between family cohesion and adolescent alcohol use. Journal of Child and Family Studies, 25, 1269-1283.

Substance Abuse and Mental Health Services Administration. (2007). The OAS report: A day in the life of American adolescents: Substance use facts. Rockville, MD: Substance Abuse and Mental Health Services Administration.

Sullivan, P. F., \& Kendler, K. S. (1999). The genetic epidemiology of smoking. Nicotine \& Tobacco Research, 1(Suppl. 2), S51-S57.

U.S. Department of Health and Human Services. (1994). Preventing tobacco use among young people: A report of the Surgeon General. Atlanta, GA: Centers for Disease Control and Prevention.

Unger, J. B., Lessov-Schlaggar, C. N., Pang, Z., Guo, Q., Ning, F., Gallaher, P., ... Johnson, C. A. (2011). Heritability of smoking, alcohol use, and psychological characteristics among adolescent twins in Qingdao, China. Asia-Pacific Journal of Public Health, 23, 568-580.

Vink, J. M., Willemsen, G., \& Boomsma, D. I. (2003). The association of current smoking behavior with the smoking behavior of parents, siblings, friends and spouses. Addiction, 98, 923-931.

Young, S. E., Rhee, S. H., Stallings, M. C., Corley, R. P., \& Hewitt, J. K. (2006). Genetic and environmental vulnerabilities underlying adolescent substance use and problem use: General or specific?. Behavior Genetics, 36, 603-615. 